\title{
The Role of Sequestrene 138 in Highbush Blueberry (Vaccinium corymbosum L.) Micropropagation
}

\author{
Doina Clapa and Claudiu Bunea \\ University of Agricultural Sciences and Veterinary Medicine Cluj-Napocal \\ Horticulture Research Station, Mănăştur 3-5, 400372, Cluj-Napoca, Romania
}

Orsolya Borsai ${ }^{1}$, Adela Pintea, Monica Hârța, and Răzvan Ştefan

University of Agricultural Sciences and Veterinary Medicine Cluj-Napoca, Mănăştur 3-5, 400372, Cluj-Napoca, Romania

\section{Alexandru Fira \\ Industrial Plants Ltd., Kazanlak, Bulgaria}

Additional index words. photosynthetic pigments, FeNaEDDHA, in vitro, woody plant medium

\begin{abstract}
The current research was carried out to investigate the effects of iron source in the culture media for Vaccinium corymbosum L. 'Blueray', 'Duke', and 'Patriot' cultivars grown on five different types of medium (Woody Plant Medium supplemented with 1.0 mg. $\mathrm{L}^{-1}$ zeatin and $0,25,50,75$, and $100 \mathrm{mg} \cdot \mathrm{L}^{-1}$ Sequestrene 138). After 10 weeks of culture, seven physiological parameters were measured, such as the number and length of axillary shoots, rooting and acclimatization percentage, as well as chlorophyll (a, $b$, a/b) and carotenoid content of the leaves. Adding Sequestrene 138 to the culture media led to a slight decrease of the proliferation rate but increased the length of the shoots. The chlorophyll and carotenoid content in all of the three cultivars was considerably increased as the iron concentration of the media increased. The shoots developed on the Sequestrene 138-free medium were chlorotic and short, whereas at different concentrations of iron in the culture medium the shoots were dark green and vigorous, providing a greater acclimatization success than those grown in iron-free medium.
\end{abstract}

The genus Vaccinium is a member of the Ericaceae family, which includes $\approx 400$ species. Of all the cultivated species and hybrids in this genus, highbush blueberry ( $V$. corymbosum L.) is the most commonly known species that produces small, edible fruits containing high amounts of antioxidants, phenolic compounds, and vitamins with a remarkable ability to provide high yields with minimal inputs (López et al., 2010; Prodorutti et al., 2007; Samad et al., 2014; Zheng and Wang, 2003). Due to the valuable pharmaceutical properties of the fruits, blueberry production has been increased considerably in the recent years. Therefore, to satisfy the high demand for blueberries, a new and commercially viable

Received for publication 21 June 2018. Accepted for publication 7 Aug. 2018.

This work was made possible with the financial support of the Romanian National Authority for Scientific Research and Innovation, National Scientific Research Council/Advisory Board for Research, Development and Innovation-Executive Agency for Higher Education, Research, Development and Innovation Funding (CNCS/CCCDI-UEFISCDI), project number PN-III-P2-2.1.-BG-2016-0046, within PNCDI III.

${ }^{1}$ Corresponding author. E-mail: borsaiorsi@yahoo. com.

This is an open access article distributed under the CC BY-NC-ND license (http://creativecommons. org/licenses/by-nc-nd/4.0/). way to produce homogeneous and disease-free blueberry plants in a short time is required (Gao et al., 2018).

Research on highbush blueberry micropropagation was started in the 1980s (Reed and Abdelnour-Esquivel, 1991) and then broadened and accelerated in recent years to improve the existing micropropagation protocols (Gao et al., 2018; Hung et al., 2016; Kudryashova et al., 2012; Ružić et al., 2012). In the beginning, research was focused on finding the optimal culture media for micropropagation and checking the influence of diverse growth regulators (Chandler and Draper, 1986; Da Silva et al., 2006; Eccher and Noe, 1989; Eccher et al., 1986; Gajdošová et al., 2006; Isutsa et al., 1994; Ostrolucká et al., 2002, 2004; Reed and Abdelnour-Esquivel, 1991; Tetsumura et al., 2008; Zhang et al., 2006). The results showed that the most suitable medium for this species was McCown's Woody Plant Basal Salt Mixture, or Woody Plant Medium (WPM), as described by Lloyd and McCown (1980). In the following years, the influence of different plant hormones on the efficiency of in vitro regeneration of highbush blueberry was studied (Kudryashova et al., 2012), and other investigations also were made on the antioxidant and anti-inflammatory properties of V. corymbosum L. (Samad et al., 2014).

The latest scientific research was carried out to investigate the hyperhydricity-induced ultrastructural and physiological changes in blueberry (Gao et al., 2018), the effects of LED lights used for in vitro culture (Hung et al., 2016), the effect of 24-epibrassinolide on in vitro micropropagation of highbush blueberry (Kudryashova et al., 2012), and the use of a bioreactor in lowbush blueberry micropropagation (Debnath, 2009).

Leaf pigment content and composition also provide important information about the physiological status of the in vitro plant. Several studies have been conducted on this topic to investigate the effects of iron chelates [FeEDTA (iron-ethylenediaminetetraacetate) and FeEDDHA (ferric sodium ethylenediamine di-2-hydroxyphenylacetic acid)] on in vitro plants for different plant species such as Rosa hybrida L. 'Moneyway' (Van der Salm et al., 1994), Carica papaya L. (Castillo et al., 1997), Citrullus lanatus (Thomas et al., 2000), hybrid hazelnut (Garrison et al., 2013; Nas and Read, 2001), and in five different raspberry cultivars (Zawadzka and Orlikowska, 2006), analyzing the chlorophyll content and chlorosis occurrence in the in vitro plants. The results show that iron chelates have beneficial effects on in vitro plants, but to the best of our knowledge, no scientific reports have been published on this topic in highbush blueberry in vitro plants. Therefore, the main aim of this paper was to investigate the influence of four different concentrations of Sequestrene 138 [ferric sodium ethylenediamine di-2-hydroxy-phenylacetic acid (FeNaEDDHA)] on the physiological status of the in vitro-propagated highbush blueberry plants represented by the number and length of the proliferated shoots, photosynthetic pigment content of the leaves, and, last but not least, rooting and acclimatization rates.

\section{Materials and Methods}

Plant material and culture conditions. This research was carried out in the Life Science Institute of University of Agricultural Sciences and Veterinary Medicine Cluj-Napoca, Romania, for 5 months, from Jan. to May 2017.

The plant material used consisted of the in vitro-propagated plants from three different highbush blueberry (Vaccinium corymbosum L.) cultivars as follows: Blueray, Duke, and Patriot. The mini-shoots with lengths of 1.5 to $2 \mathrm{~cm}$ used in this experiment were taken from the 10 -week-old in vitro plantlets cultured on a medium prepared from stock solutions having the following composition: WPM (Lloyd and McCown, 1980), $100 \mathrm{mg} \cdot \mathrm{L}^{-1}$ Sequestrene 138 (FeNaEDDHA 6\%), $100 \mathrm{mg} \cdot \mathrm{L}^{-1}$ myo-inositol, $2 \mathrm{mg} \cdot \mathrm{L}^{-1}$ vitamin $\mathrm{B} 1,1 \mathrm{mg} \cdot \mathrm{L}^{-1}$ vitamin $\mathrm{B} 6$, $1 \mathrm{mg} \cdot \mathrm{L}^{-1}$ nicotinic acid, $1 \mathrm{mg} \cdot \mathrm{L}^{-1}$ zeatin, and $3 \%(\mathrm{w} / \mathrm{v})$ of sugar.

To check the influence of Sequestrene 138 on the micropropagation success of highbush blueberry plants, WPM (Duchefa Biochemie $\mathrm{BV}$, The Netherlands) was used supplemented with $1 \mathrm{mg} \cdot \mathrm{L}^{-1}$ zeatin, $3 \%(\mathrm{w} / \mathrm{v})$ of sugar, and $0,25,50,75$, and $100 \mathrm{mg} \cdot \mathrm{L}^{-1}$ Sequestrene 138, respectively.

The culture medium was solidified with $0.35 \%(\mathrm{w} / \mathrm{v})$ plant agar. All the components were purchased from Duchefa Biochemie 
$\mathrm{BV}$. The $\mathrm{pH}$ of the media was adjusted to 5.0 before autoclaving. The autoclave program used for sterilizing the culture media was run at $0.11 \mathrm{MPa}$ at $121{ }^{\circ} \mathrm{C}$ for $20 \mathrm{~min}$.

The culture vessels used in this experiment were 720 glass jars, with a diameter of $9 \mathrm{~cm}$ and a height of $13.5 \mathrm{~cm}$ with sponge-vented screw caps. In each vessel, $100 \mathrm{~mL}$ of culture medium was dispensed for culturing. The in vitro cultures were incubated in the growth room for a 16-h photoperiod with $32.4 \mu \mathrm{mol} \cdot \mathrm{m}^{-2} \cdot \mathrm{s}^{-1}$ light intensity (Cool white fluorescent lamps, $36 \mathrm{~W}$; Philips, Amsterdam, The Netherlands) at $23 \pm 3{ }^{\circ} \mathrm{C}$ and $50 \% \pm 2 \%$ humidity.

Ten explants per jar with a length of 1.5 to 2 $\mathrm{cm}$ were inoculated in such way that two-thirds to three-fourths of the basal part of the explants was immersed in the culture media. The length of the shoots and the multiplication rate were recorded and calculated after 10 weeks of culture. In total, 50 randomly selected plantlets (five jars per treatment per cultivar) were measured.

Ex vitro rooting and acclimatization. The shoots obtained in the multiplication stage were acclimatized in a nonsterile mixture of peat [Klasmann-Deilmann, Lithuanian Peat Moss Special Ericaceous plants, $\mathrm{pH}$ value $\left(\mathrm{H}_{2} \mathrm{O}\right)$ : 4.0-4.5, structure: medium, without fertilization] and perlite ('BIOS' Research and Development Center of Bio-stimulators, Cluj-Napoca, Romania) in 1:1 (v:v) ratio, in mini-greenhouses [Versay T1 (DEDEMAN SRL, Bacău, Romania), sizes $39 \times 25 \times 7.5 \mathrm{~cm}$, polyvinyl chloride], in laboratory conditions. For acclimatization, only shoots longer than $2.5 \mathrm{~cm}$ were used.

To determine the rooting and acclimatization percentage of the in vitro plantlets, five repetitions with 32 shoots per treatment for each cultivar and rooting substrate (160 shoots per rooting substrate, 800 shoots per cultivar, in total 2400 shoots) were used. The rooting and acclimatization data and percentage were recorded and calculated after $30 \mathrm{~d}$.

Chlorophyll content. To measure the fresh chlorophyll content, leaves were harvested from the in vitro plantlets before passing them to the acclimatization stage. Fresh samples $(0.2$ g) were homogenized and extracted with $90 \%$ acetone in water using a magnetic stirrer until the residue was uncolored. The absorbance was read at 645 and $663 \mathrm{~nm}$ using the V-530 UV/ VIS Spectrophotometer (JASCO, Eason, MD). The following formulas were used to quantify chlorophyll a (Chl a) and chlorophyll b (Chl b) and to check the ratio between $\mathrm{Chl} a$ and $b$ (Chl a/Chl b):

$$
\begin{aligned}
& \text { Chl } a(m g / g) \\
& \quad=(11.75 \times A 663-2.35 \times A 645) \times V / g
\end{aligned}
$$

$$
\begin{aligned}
& \text { Chl } b(m g / g) \\
& \quad=(18.61 \times A 645-3.96 \times A 663) \times V / g
\end{aligned}
$$

where $A 645$ and $A 663$ represent the optical density at specific wavelength, $V$ represents the volume of the extract $(\mathrm{mL})$, and $g$ represents sample s weight (mg).

Carotenoid (Caro) content. The extraction of Caro was carried out with acetone using fresh leaf samples and repeated until the residue became uncolored. The combined extracts were partitioned in a separation funnel with diethyl ether and saturated saline solution. The upper organic phase was evaporated to dryness under vacuum, using a rotary evaporator, then the residue was dissolved in a measured volume of diethyl ether and treated with an equal volume of $30 \%$ potassium hydroxide in methanol for saponification. Furthermore, the samples were stirred for $2 \mathrm{~h}$, then transferred in a separation funnel and washed with saline solution until neutral $\mathrm{pH}$ of the aqueous phase was

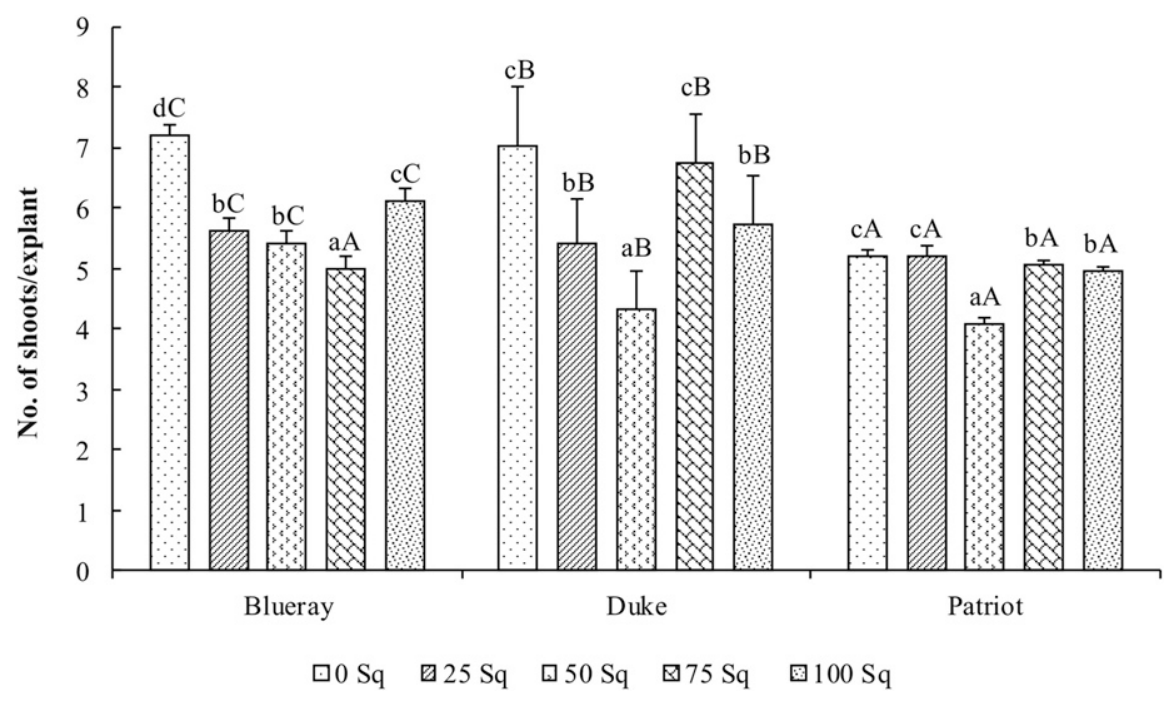

Fig. 1. The influence of Sequestrene 138 on the number of shoots per explant developed on the medium supplemented with the indicated Sequestrene $138\left(\mathrm{mg} \cdot \mathrm{L}^{-1}\right)$ concentrations. The values shown are means $\pm \operatorname{SE}(n=5)$. Different lowercase letters above the bars indicate significant differences between treatments for each cultivar, and different capital letters indicate significant differences between the cultivars for each treatment, according to Tukey's test $(P \leq 0.05)$.

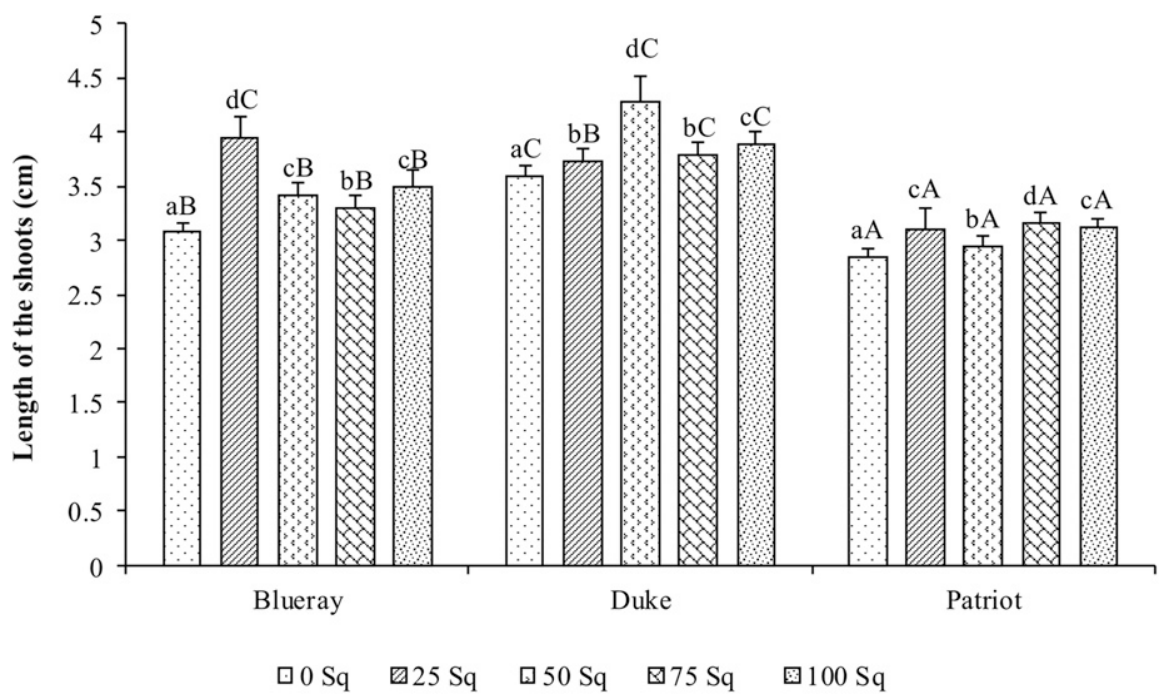

Fig. 2. The influence of Sequestrene 138 on the length of shoots grown on the medium supplemented with the indicated Sequestrene $138\left(\mathrm{mg} \cdot \mathrm{L}^{-1}\right)$ concentrations. The values shown are means $\pm \mathrm{SE}(\mathrm{n}=5)$. Different lowercase letters above the bars indicate significant differences between treatments for each cultivar, and different capital letters indicate significant differences between the cultivars for each treatment, according to Tukey's test $(P \leq 0.05)$.

Table 1. Acclimatization percentage of the in vitro-cultured plants in the three different cultivars.

\begin{tabular}{lccccc}
\hline & \multicolumn{5}{c}{$\mathrm{WPM}+$ Sequestrene 138} \\
\cline { 2 - 6 } Cultivar & $0 \mathrm{mg} \cdot \mathrm{L}^{-1}$ & $25 \mathrm{mg} \cdot \mathrm{L}^{-1}$ & $50 \mathrm{mg} \cdot \mathrm{L}^{-1}$ & $75 \mathrm{mg} \cdot \mathrm{L}^{-1}$ & $100 \mathrm{mg} \cdot \mathrm{L}^{-1}$ \\
\hline Blueray & $96.250 \pm 0.583$ & $98.125 \pm 0.400$ & 100 & 100 & 100 \\
Duke & $95.000 \pm 0.509$ & $96.875 \pm 0.547$ & 100 & 100 & \\
& & $98.125 \pm 0.244$ & & & 100 \\
Patriot & $94.375 \pm 0.583$ & $99.375 \pm 0.200$ & $98.750 \pm 0.244$ & 100 & 100 \\
\hline
\end{tabular}


obtained. After the separation, the organic phase was dried over anhydrous sodium sulfate until the solvent evaporated. Finally, the residue was dissolved in a known volume of hexane and the measurments were recorded at $450-\mathrm{nm}$ absorbance level using the V-530 UV/VIS Spectrophotometer (JASCO) (Britton et al., 1995). The concentration of total Caro was calculated according to the formula to follow:

$$
\begin{aligned}
& X(m g \text { carotenoids }) \\
& =(A \times V \times 1000) /(A 1 \% 1 \mathrm{~cm} \times 1 \times 100)
\end{aligned}
$$

where $A$ represents absorbance at $450 \mathrm{~nm}, V$ represents volume $(\mathrm{mL})$, and $A 1 \% 1 \mathrm{~cm}=$ 2500 and expressed as $\mathrm{mg}$ Caro/g fresh material (Britton et al., 1995). All experiments were done under subdued light.

Statistical analysis. One-way analysis of variance (ANOVA) was performed for treatments within one cultivar and for all the cultivars within one treatment to investigate whether the differences in physiological parameters of the in vitro plants were affected by the presence of different concentrations of Sequestrene 138 added to the culture media. Post hoc testing for the ANOVAs was performed using Tukey's honestly significant difference test (Tukey's test) using a $P \leq$ 0.05 significance level to determine the statistically significant differences between the means. Values shown are means \pm SE. In addition, all variables determined in plants submitted to iron treatments were correlated by principal component analysis (PCA), independently for each of the three studied $V$. corymbosum L. cultivars. Each principal component was a linear combination of the original variables with coefficients equal or greater than eigenvectors of the correlation matrix. The results of these analyses were represented graphically, for each species, as a biplot of the two main principal components.

\section{Results}

Effect of Sequestrene 138 on in vitro shoot multiplication of Vaccinium corymbosum $L$. 'Blueray', 'Duke', and 'Patriot'. The greatest multiplication rates were recorded on the WPM [containing $36.7 \mathrm{mg} \cdot \mathrm{L}^{-1}$ ferric sodium ethylenediamine tetra acetic acid (FeNaEDTA)] as compared with the other culture media supplemented with different concentrations of Sequestrene 138 used in this experiment. Among all the highbush blueberry cultivars tested, the greatest shoot proliferation rate $(7.2 \pm 0.9927)$ was observed in 'Blueray' (Fig. 1) with the exception of the medium supplemented with $75 \mathrm{mg} \cdot \mathrm{L}^{-1}$ Sequestrene 138. 'Blueray' had the greatest proliferation rates in all types of media tested, whereas the lowest proliferation rates were recorded in 'Patriot', ranging from $4.08 \pm 0.0902$ to $5.22 \pm 0.1501$.

Regarding shoot lengths, it was observed that in all cultivars the average length of the shoots obtained on the medium supplemented with Sequestrene was significantly larger as compared with control (Fig. 2).

On the WPM basal medium, whereas the shortest shoots were obtained in 'Patriot', with an average length of $2.84 \pm 0.0655$, the longests were recorded in 'Duke', with an average length of $3.59 \pm 0.0976 \mathrm{~cm}$. The concentration given by $50 \mathrm{mg} \cdot \mathrm{L}^{-1}$ Sequestrene 138 stimulated the growth of the shoots in 'Duke' $(4.28 \pm 0.2278 \mathrm{~cm})$.

The shortest shoots on the WPM basal medium were recorded in 'Patriot', with an average length of $2.84 \pm 0.0655 \mathrm{~cm}$, but the longests were measured in 'Duke', with an average length of $3.59 \pm 0.0976 \mathrm{~cm}$. In 'Blueray', the average length of the shoots developed was $3.07 \pm 0.0897 \mathrm{~cm}$. The 50 $\mathrm{mg} \cdot \mathrm{L}^{-1}$ concentration of Sequestrene 138 had a beneficial effect on shoot growth also in 'Duke' $(4.28 \pm 0.2278 \mathrm{~cm})$, but the longest shoots were recorded in 'Blueray' (with an average length of $3.94 \pm 0.1952 \mathrm{~cm}$ ) on the WPM basal medium supplemented with 25 $\mathrm{mg} \cdot \mathrm{L}^{-1}$ of Sequestrene 138. The longest shoots in 'Patriot' were obtained on the medium supplemented with $75 \mathrm{mg} \cdot \mathrm{L}^{-1}$ and $100 \mathrm{mg} \cdot \mathrm{L}^{-1}$ of Sequestrene (no statistically significant differences were observed between them).

Effects of Sequestrene 138 on ex vitro rooting and acclimatization of 'Blueray', 'Duke', and 'Patriot' in vitro plantlets. The ex vitro rooting and acclimatization were carried out simultaneously using the shoots resulting from the multiplication stage. The shoots developed on the Sequestrene-free medium had the lowest acclimatization percentage, whereas those grown on the media with 75 and $100 \mathrm{mg} \cdot \mathrm{L}^{-1}$ Sequestrene had the greatest acclimatization percentage (Table1). 'Blueray' had the most successful rooting and acclimatization percentages, ranging from $96.25 \%$ to $100 \% ; 96.25 \%$ was registered for the shoots developed on the Sequestrene-free medium; $98.12 \%$ for the shoots obtained on the medium supplemented with $25 \mathrm{mg} \cdot \mathrm{L}^{-1}$ Sequestrene; and $100 \%$ for the shoots grown on the medium supplemented with 50, 75, and $100 \mathrm{mg} \cdot \mathrm{L}^{-1}$ Sequestrene, respectively.

Effect of Sequestrene 138 on chlorophyll and Caro content of the leaves in 'Blueray', 'Duke', and 'Patriot' in vitro plantlets. The photosynthetic pigments were quantified (Chl a, Chl b, Chl a/Chl b, and Caro) to determine the relationship between the pigment content in the leaves of the in vitro plants and the concentration of Sequestrene 138 (Figs. 3-5). In all three $V$. corymbosum L. cultivars, the photosynthetic pigment content of the leaves was increased by increasing the concentration of Sequestrene 138 in the culture media. In all the three cultivars, the greatest $\mathrm{Chl}$ a content was registered in the leaves developed on the medium supplemented with $100 \mathrm{mg} \cdot \mathrm{L}^{-1}$ Sequestrene 138, but the lowest statistically significant values of the $\mathrm{Chl}$ a content in all the cultivars were recorded in the leaves of the plantlets grown on the Sequestrene 138-free medium. Both, the highest and the lowest $\mathrm{Chl}$ a content among the cultivars studied were recorded in 'Duke', with a mean value of $2.729 \pm$ $0.0083 \mathrm{mg} / \mathrm{g}$ and $0.260 \pm 0.0070 \mathrm{mg} / \mathrm{g}$, respectively (Fig. 3).

Except for 'Blueray', the Chl b content in the leaves analyzed showed a similar increasing tendency in all the three investigated cultivars on the medium supplemented with $100 \mathrm{mg} \cdot \mathrm{L}^{-1}$ Sequestrene 138. In 'Blueray', the maximum $\mathrm{Chl} b$ content was recorded in the leaves developed on the WPM basal medium supplemented with $50 \mathrm{mg} \cdot \mathrm{L}^{-1}$ Sequestrene 138. Similar to the Chl a content, in 'Duke' both were recorded, the highest and the lowest $\mathrm{Chl} \mathrm{b}$ content, in the leaves developed on the WPM basal medium supplemented

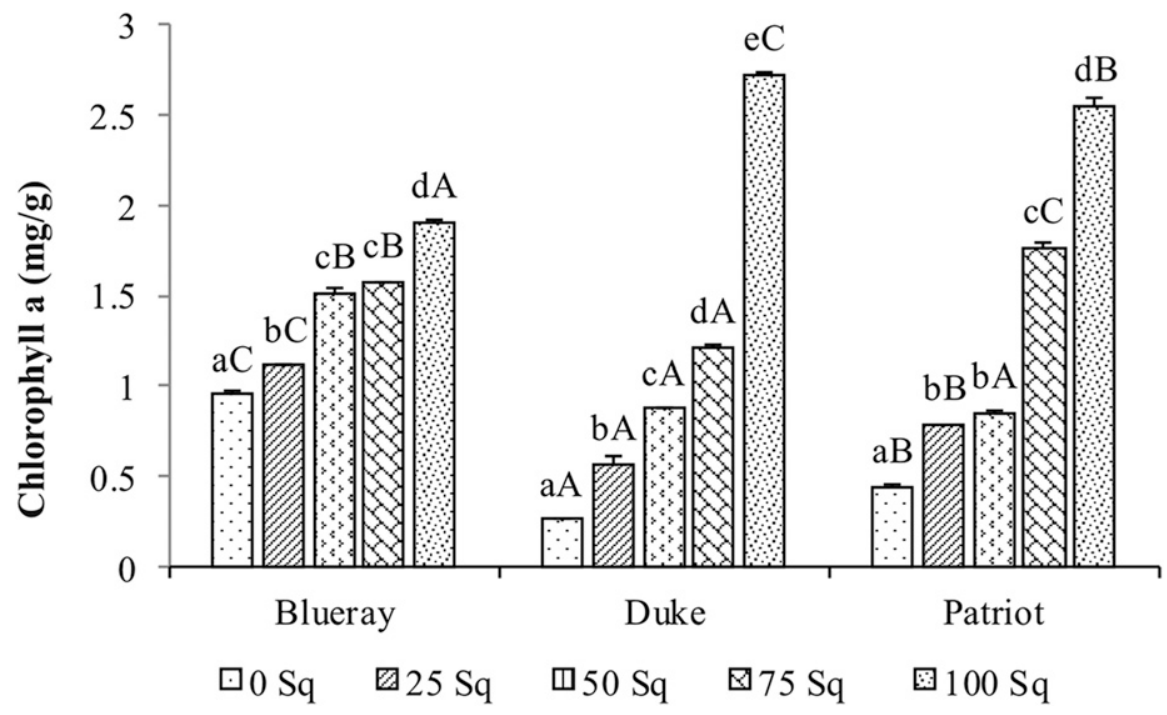

Fig. 3. The influence of Sequestrene 138 on chlorophyll a content of the leaves of the in vitro plantlets grown on the medium supplemented with the indicated Sequestrene $138\left(\mathrm{mg} \cdot \mathrm{L}^{-1}\right)$ concentrations. The values shown are means $\pm \mathrm{SE}(\mathrm{n}=5)$. Different lowercase letters above the bars indicate significant differences between treatments for each cultivar, and different capital letters indicate significant differences between the cultivars for each treatment, according to Tukey's test $(P \leq 0.05)$. 


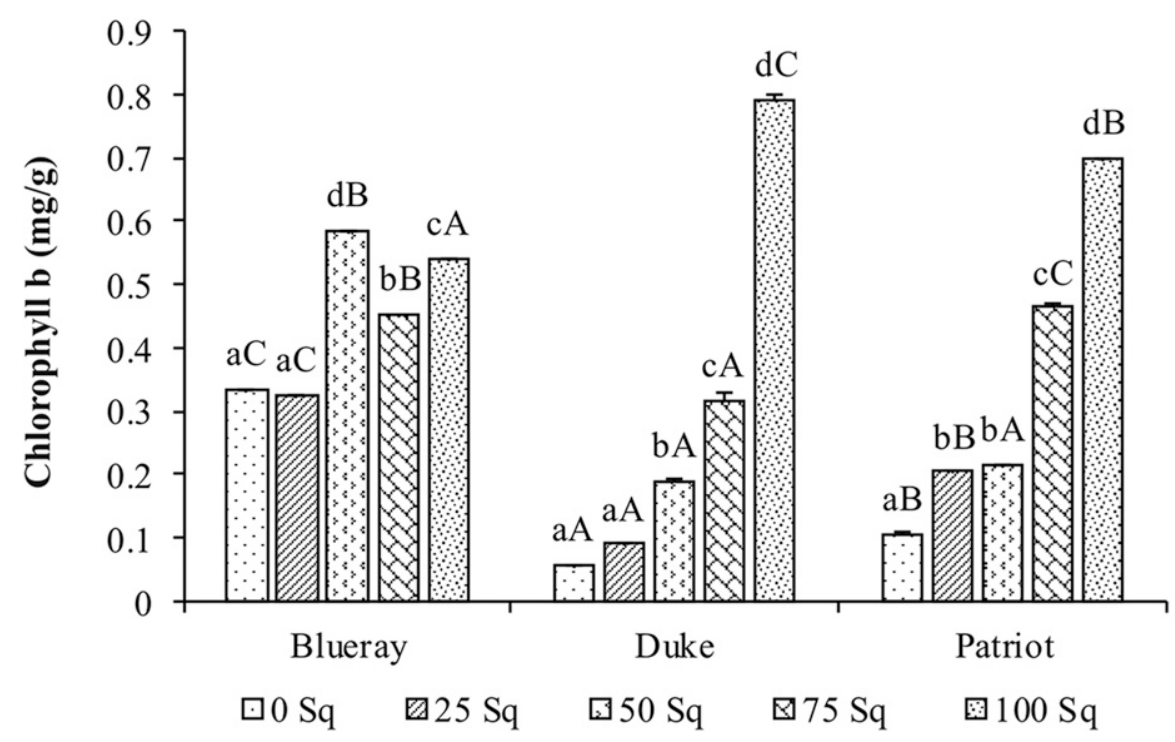

Fig. 4. The influence of Sequestrene 138 on chlorophyll b content of the leaves of the in vitro plantlets grown on the medium supplemented with the indicated Sequestrene $138\left(\mathrm{mg} \cdot \mathrm{L}^{-1}\right)$ concentrations. The values shown are means \pm SE $(n=5)$. Different lowercase letters above the bars indicate significant differences between treatments for each cultivar, and different capital letters indicate significant differences between the cultivars for each treatment, according to Tukey's test $(P \leq 0.05)$.

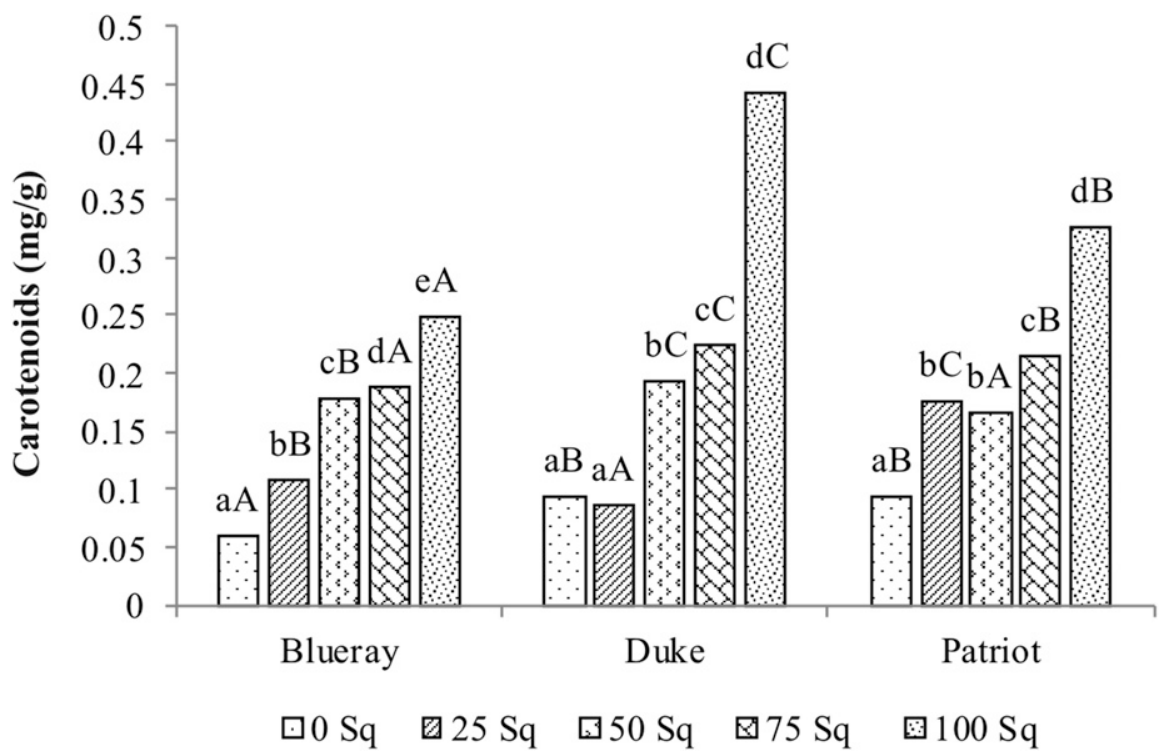

Fig. 5. The influence of Sequestrene 138 on the carotenoid content of the leaves of the in vitro plantlets grown on the medium supplemented with the indicated Sequestrene $138\left(\mathrm{mg} \cdot \mathrm{L}^{-1}\right)$ concentrations. The values shown are means \pm SE $(n=5)$. Different lowercase letters above the bars indicate significant differences between treatments for each cultivar, and different capital letters indicate significant differences between the cultivars for each treatment, according to Tukey's test $(P \leq 0.05)$.

with $100 \mathrm{mg} \cdot \mathrm{L}^{-1}$ Sequestrene 138 as follows: $0.790 \pm 0.0105 \mathrm{mg} / \mathrm{g}$ and $0.057 \pm 0.0000 \mathrm{mg} / \mathrm{g}$, respectively. Regarding $\mathrm{Chl} \mathrm{a} / \mathrm{Chl} \mathrm{b}$ ratios, the greatest values were recorded in the 0 and 25 $\mathrm{mg} \cdot \mathrm{L}^{-1}$ Sequestrene 138 treatments, which indicate iron deficiency in plants and also a lower chlorophyll content as previously confirmed by other researches in other species such as Beta vulgaris (Spiller and Terry, 1980) and Corylus avellana L. (Garrison et al., 2013).

It also was observed that the increasing concentration of Sequestrene 138 in the culture media led to a greater accumulation dataset. In the three PCAs shown in Fig. 6, two components with an eigenvalue equal to or greater than 1 expressed a cumulative percentage of variance of about $92 \%$. The first component ( $\mathrm{X}$ axis) was determined by the Sequestrene 138 concentrations of the medium (Table 1) and alone explains $63 \%$ to $71 \%$ of the variance. The iron chelate concentration of the medium was weakly correlated, negatively, with the number of shoots developed and positively with the other parameters analyzed. The small angles of the loading vectors of ACL and Caro with the X-axis indicate the strongest, positive correlations. Positive correlations, albeit weaker, also were registered between $\mathrm{Chl}$ a, Chl b, and LS and the X-axis.

\section{Discussion}

In all the three Vaccinium corymbosum $\mathrm{L}$. cultivars cultured on the standard WPM basal medium supplemented with $1 \mathrm{mg} \cdot \mathrm{L}^{-1}$ zeatin, $3 \%(\mathrm{w} / \mathrm{v})$ sugar, gelled with $0.35 \%(\mathrm{w} / \mathrm{v})$ plant agar with a $\mathrm{pH}$ adjusted to 5 , it was observed that iron chlorosis was predominant (Fig. 7). This phenomenon could be explained by the iron deficiency of the culture medium as observed in other in vitro cultures as well. Thus, it was found by Zawadzka and Orlikowska (2006) that supplementing the multiplication media with FeNaEDDHA eliminated leaf chlorosis in raspbery in 4 weeks. The leaves harvested from these shoots maintenaned their green color on the regeneration medium longer than those from FeEDDHA-free medium (Zawadzka and Orlikowska, 2006). The results obtained by Nas and Read (2001) indicate that Sequestrene 138 is a suitable chelating agent for hazelnut tissue culture. The enhanced leaf color and morphology on medium containing Sequestrene 138 compared with ferrous sulfate and Sequestrene 330 are likely a consequence of improved $\mathrm{Fe}$ availability for the explants. A previous study has shown that Sequestrene 138 yielded better results than FeNaEDTA in blueberry in vitro culture, conferring dark green color to the plants and increasing the multiplication rate and plant vigor in 'Blue Crop' (Clapa et al., 2007). Similar studies made on blueberry indicate that supplementing the basal WPM medium with $100 \mathrm{mg} \cdot \mathrm{L}^{-1}$ Sequestrene 138 (WPMm) in combination with growth regulators led to a high proliferation rate in Elliot bluberry cultivar and the greatest number of shoots developed per explant (14.85) on the WPMm + $2 \mathrm{mg} \cdot \mathrm{L}^{-1}$ zeatin (Vescan et al., 2012).

In a previous investigation, differences were observed regarding the color of the shoots in the initiation stage of in vitro cultures in blueberry cultivars such as Berkeley, Bluecrop, and Earliblue on three different culture media, as follows: MS (Murashige and Skoog, 1962), WPM, and MW (a mixture of equal parts of MS and WPM). The color of the shoots varied from one cultivar to another; $80 \%$ of shoots from 'Bluecrop' and 'Earliblue' explants were yellowish green, and $30 \%$ of 'Berkeley' shoots were red regardless of the medium (Tetsumura et al., 


\section{Blueray (A)}

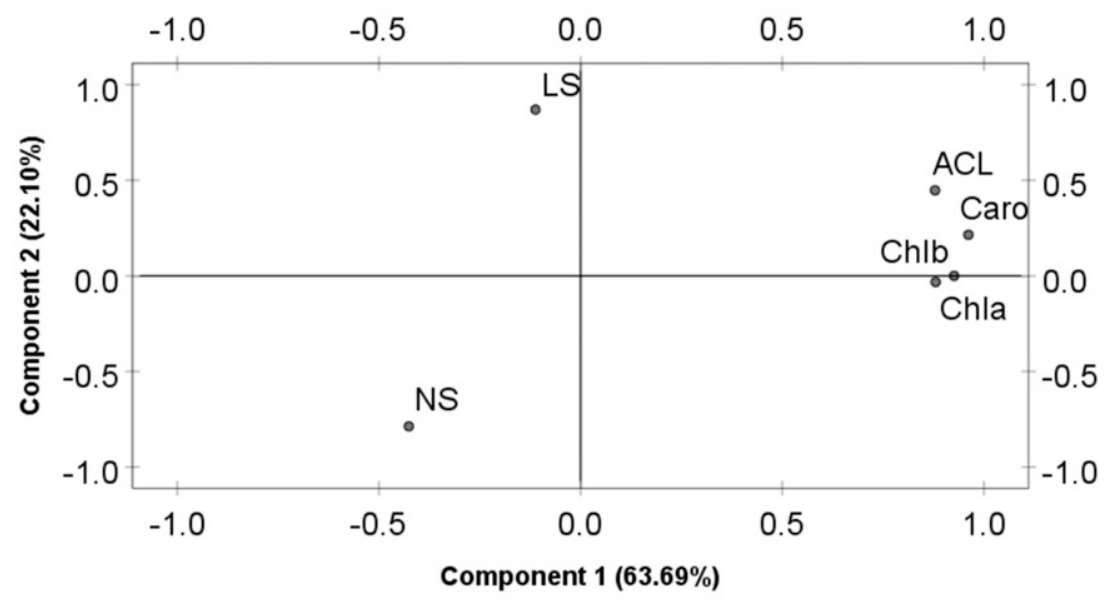

Duke (B)

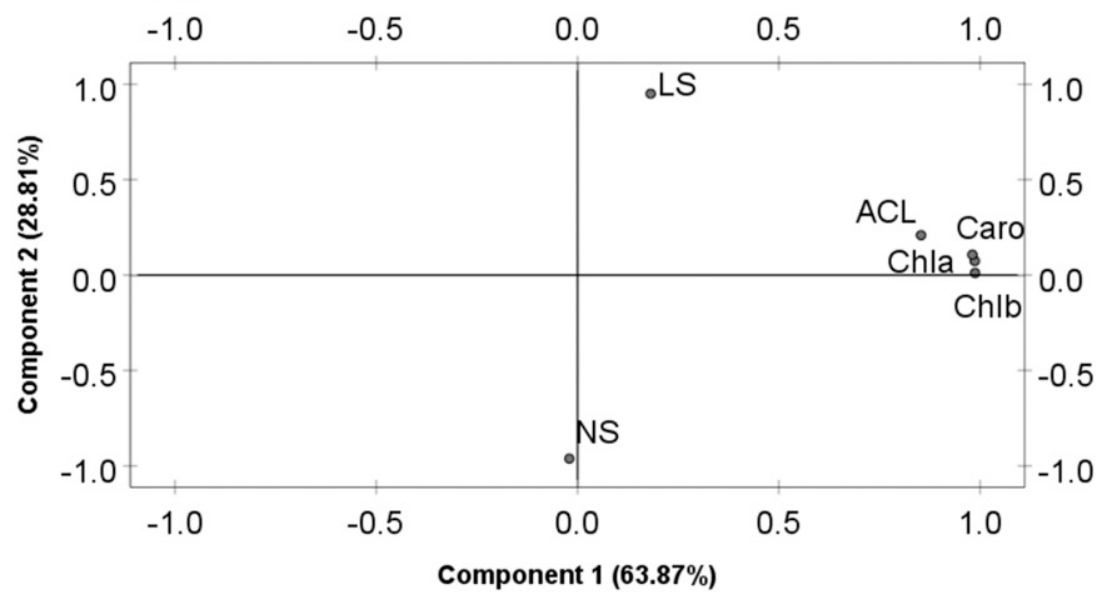

\section{Patriot (C)}

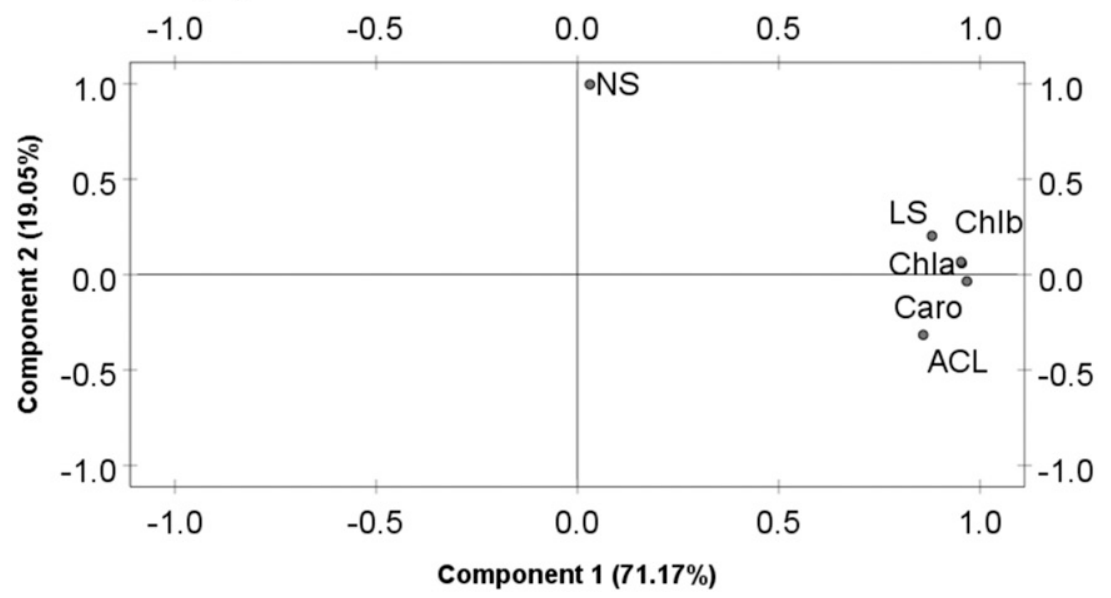

Fig. 6. Principal component analysis. Changes in all the measured parameters with respect to the control, iron-free medium in Vaccinium corymbosum L. Blueray in correlation to the iron concentration of the culture medium. The parameters examined were length of the shoots (LS), number of shoots (NS), Chlorophyll a (Chl a), Chlorophyll b (Chl b), Carotenoids (Caro), and acclimatization percentage (ACL): 'Blueray' (A), 'Duke' (B), and 'Patriot' (C).

2008). Our results show that the basal WPM medium supplemented with the four different Sequestrene 138 (FeNaEDDHA) concentrations had a significant impact on the shoot length reached in the multiplication stage in all the cultivars studied (Fig. 2). Studies also suggest that there is a slight difference between the responses of the blueberry cultivars to the iron chelate concentrations applied to the culture medium (Reed and Abdelnour-Esquivel, 1991;
Ružić et al., 2012; Tetsumura et al., 2008). In this research, it was observed that the length of the shoots varied among the cultivars on all types of media; the longest shoots developed being recorded in 'Duke', followed by 'Blueray', whereas the shortest shoots were measured in 'Patriot'. A slight decrease also was observed in the number of shoots per explant on the media supplemented with iron chelate (Fig. 1). Although the proliferation rate was greater on the Sequestrene 138-free medium, the shoots developed were shorter and yellowish. For this reason, some of the shoots $(<2 \mathrm{~cm})$ were eliminated from the ex vitro rooting stage, and others didn't regenerate roots due to chlorosis. In this context, in 'Blueray', the average number of shoots per explant that occurred was greater $(7.2 \pm 0.1621)$ on the basal WPM medium in comparison with the number of shoots per explant obtained on the medium supplemented with $100 \mathrm{mg} \cdot \mathrm{L}^{-1}$ Sequestrene 138, reaching an average number of $6.12 \pm 0.2191 /$ explant. The rooting and ex vitro acclimatization percentage recorded in the shoots obtained from the iron-free medium was $96.250 \pm 0.583 \%$, whereas the acclimatization percentage of the shoots obtained from the medium supplemented with $100 \mathrm{mg} \cdot \mathrm{L}^{-1}$ Sequestrene 138 was 100 (Table 1).

Blueberry plants have a remarkable ex vitro rooting capacity, which permits one to eliminate the in vitro rooting stage from the multiplication process, lowering the production costs in micropropagation (Isutsa et al., 1994). The ex vitro rooting percentages recorded in all the cultivars on all types of media supplemented with iron chelate are similar to the acclimatization percenteges of blueberry plants reported by Isutsa et al. (1994) in 'Berkeley' (>99\%); 100\% rooting was reported by Hung et al. (2016) in the ex vitro rooting stage of 'Huron' shoots in a nonsterile mixture of perlite and peatmoss (Top Blueberry Co., Cheonan, South Korea) $(\mathrm{v} / \mathrm{v}=1: 6)$. These results are in accordance with our results obtained in the shoots grown on the culture medium supplemented with 75 $\mathrm{mg} \cdot \mathrm{L}^{-1}$ and $100 \mathrm{mg} \cdot \mathrm{L}^{-1}$ Sequestrene 138.

The results reveal that chlorophyll $a, b$,

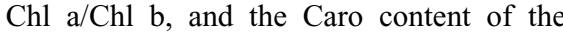
leaves of the in vitro plants were significantly influenced by the increasing concentration of iron chelate added to the culture medium. The chlorophyll content of the leaves is one of the most important and reliable indicators of physiological status of the plants. This aspect is very important for the evolution of the in vitro cultures; namely, the low chlorophyll content can affect photosynthesis, leading to a low acclimatization rate and unsatisfactory plant growth and development (Rafi et al., 2018). Similar results also were reported by Van der Salm et al. (1994), who investigated the effects of iron chelates in Rosa hybrida L. 'Moneyway' in vitro cultures. The authors claim that the use of FeEDDHA is more effective. We can hypothesize that the replacement of FeNaEDTA by FeNaEDDHA in media also will improve the in vitro culture of other plant species that are susceptible to iron deficiency. Also, in 


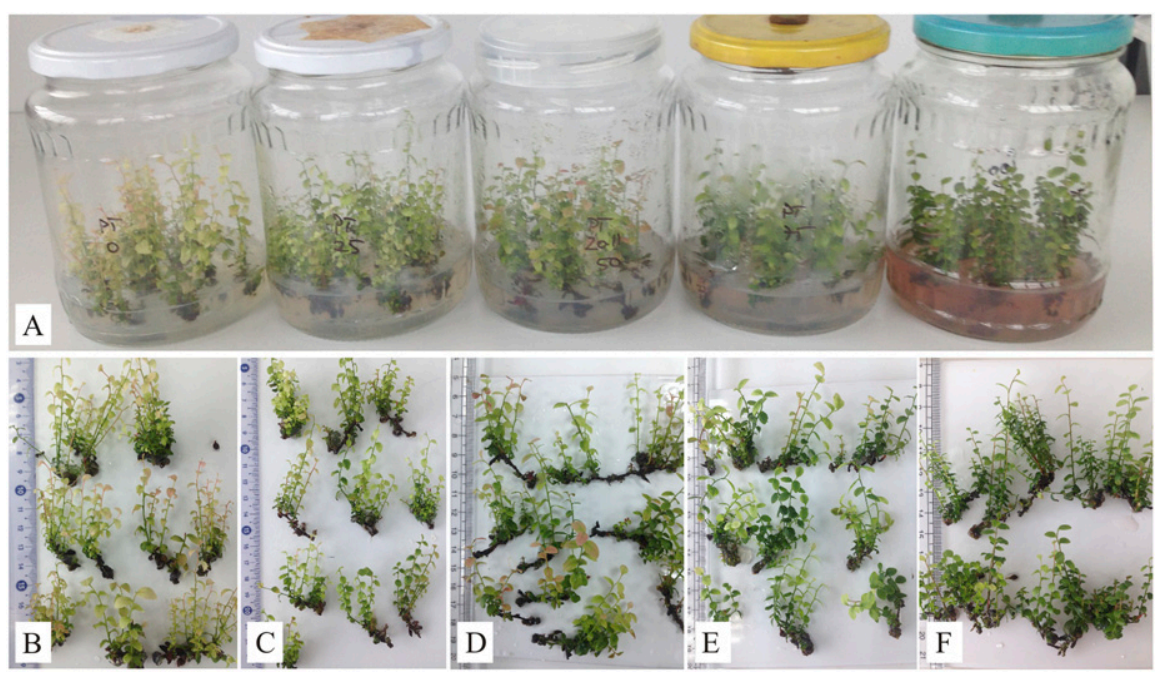

Fig. 7. In vitro cultured $V$. corymbosum L. 'Patriot' plants on the five different types of medium supplemented with Sequestrene 138 (from the left to the right: 0, 25, 50, 77, and $100 \mathrm{mg} \cdot \mathrm{L}^{-1}$ Sequestrene 138) (A); shoots of 'Patriot' grown on the iron-free WPM medium (B), shoots grown on basal WPM $+25 \mathrm{mg} \cdot \mathrm{L}^{-1}$ Sequestrene $138(\mathbf{C})$, shoots grown on basal WPM $+50 \mathrm{mg} \cdot \mathrm{L}^{-1}$ Sequestrene 138 (D), shoots grown on basal WPM $+75 \mathrm{mg} \cdot \mathrm{L}^{-1}$ Sequestrene $138(\mathbf{E})$, and shoots grown on basal $\mathrm{WPM}+100 \mathrm{mg} \cdot \mathrm{L}^{-1}$ Sequestrene $138(\mathbf{F})$.

vitro-grown Vaccinium pahalae and V. myrtillus plants as reported by Shibli et al. (1997) had a considerably better performance. Chlorosis and hyperhydration were eliminated when the iron chelate (FeNaEDTA) was replaced with or supplemented by FeNaEDDHA (Sequestrene 138-50, 100, and $150 \mu \mathrm{M}$ ). Castillo et al. (1997), in one of their studies carried out on Carica papaya L. in vitro culture, suggest that supplementing the culture media with $100 \mu \mathrm{M}$ concentration of iron provided by FeNaEDDHA may be sufficient to markedly improve in vitro culture performance.

The length of the shoots obtained in the in vitro multiplication stage, the color, and the morphology of the in vitro plants were considerably improved on the culture media supplemented with Sequestrene 138, as compared with those obtained on the basal WPM medium, as a probable consequence of the fact that the iron in this compound is more readily available to the plants. The use of Sequestrene 138 in the culture media of all cultivars resulted in a greater chlorophyll content in the leaves, a more equilibrated $\mathrm{Chl} \mathrm{a/Chl} \mathrm{b}$ ratio, and a greater micropropagation rate as compared with control.

The results of the PCAs clearly and briefly summarize the very similar pattern in the three studied cultivars, which responded very similarly to the increasing iron chelate concentration in the media. Among the three cultivars under investigation, 'Patriot' had a positive response to iron added to the culture medium, showing a strong positive correlation between iron concentration and growth parameters, whereas 'Blueray' and 'Duke' demonstrated a negative effect of the iron chelate on the number and the length of the shoots developed as the iron concentration of the medium increased. The photosythetic pigment concentrations in all three cultivars were considerably increased as the iron concentration of the medium increased. The acclimatization success of the in vitro plants grown on the medium supplemented with iron chelates was considerably greater than in those grown on iron-free medium. Therefore, based on the results of our study, we highly recommend the use of Sequestrene 138 as the main iron source in the culture medium for a succsessful micropropagation of blueberry plants.

\section{Literature Cited}

Britton, G., K. Schiedt, and S. Liaaen-Jensen. 1995. Isolation and analysis, p. 104-107. In: Carotenoids, Vol. 1A. Birkhauser Verlag, Basel.

Castillo, B., M.A.L. Smith, D.L. Madhavi, and U.L. Yadava. 1997. Interactions of irradiance level and iron chelate source during shoot tip culture of Carica papaya L. HortScience 32:1120-1123.

Chandler, C.K. and A.D. Draper. 1986. Effect of zeatin and 2ip on shoot proliferation of three blueberry clones in vitro. HortScience 21:10651066.

Clapa, D., A. Fira, and T. Rusu. 2007. The use of Isubgol and Sequestrene 138 for the in vitro propagation of the highbush blueberry (Vaccinium corymbosum L.). J. Food Agr. Environ. 6(1):145-147.

Da Silva, L.C., M.W. Schuch, J.A. De Souza, A.C. Erig, and L.E.C. Antunes. 2006. Nutritive medium, growth regulators and cold in the in vitro establishment of blueberry (Vaccinium ashei Reade) cv. 'Delite'. R. Bras. Agrociência, Pelotas 12(4):405-408.

Debnath, S.C. 2009. A scale-up system for lowbush blueberry micropropagation using a bioreactor. HortScience 44:1962-1966.

Eccher, T. and N. Noe. 1989. Comparison between $2 \mathrm{iP}$ and zeatin in the micropropagation of highbush blueberry (Vaccinium corymbosum). Acta Hort. 241:185-190.

Eccher, T., N. Noe, C. Piagnani, and S. Castelli. 1986. Effects of Increasing Concentration of $\mathrm{BAP}$ and 2iP on in vitro culture of Vaccinium corymbosum. Acta Hort. 179(II):879-881.
Gajdošová, A., M.G. Ostrolucká, G. Libiaková, E. Ondrušková, and G. Šimala. 2006. Microclonal propagation of Vaccinium sp. and Rubus sp. and detection of genetic variability in culture in vitro. J. Fruit Ornam. Plant Res. 14(1):103119.

Gao, H., J. Li, H. Ji, L. An, and X. Xia. 2018. Hyperhydricity-induced ultrastructural and physiological changes in blueberry (Vaccinium spp.). Plant Cell Tissue Organ Cult. 133:65-76.

Garrison, W., A. Dale, and P.K. Saxena. 2013. Improved shoot multiplication and development in hybrid hazelnut nodal cultures by ethylenediamine di-2-hydroxy-phenylacetic acid (Fe-EDDHA). Can. J. Plant Sci. 93(3):511521.

Hung, C.D., C.H. Hong, S.K. Kim, K.H. Lee, J.Y. Park, M.W. Nam, D.H. Choi, and H.I. Le. 2016. LED light for in vitro and ex vitro efficient growth of economically important highbush blueberry (Vaccinium corymbosum L.). Acta Physiol. Plant. 38(6):152.

Isutsa, D.K., M.P. Pritts, and K.W. Mudge. 1994. Rapid propagation of blueberry plants using ex vitro rooting and controlled acclimatization of micropropagules. HortScience 29:1124-1126.

Kudryashova, O.A., A.A. Volotovich, T.I. Vasilevskaya, N.P. Varavina, Z.A. Rupasova, and V.A. Khripach. 2012. Effects of 24epibrassinolide on in vitro micropropagation of highbush blueberry. Russ. J. Plant Physiol. 59:4):586-593.

Lloyd, G. and B. McCown. 1980. Commercially feasible micropropagation of mountain laurel, Kalmia latifolia, by use of shoot-tip culture. Comb. Proc. Intl. Plant Prop. Soc. 30:421-427.

López, J., E. Uribe, A. Vega-Gálvez, M. Miranda, J. Vergara, E. Gonzalez, and K. Di Scala. 2010. Effect of air temperature on drying kinetics, vitamin $\mathrm{C}$, antioxidant activity, total phenolic content, non-enzymatic browning and firmness of blueberries variety $\mathrm{O}$ Neil. Food Bioprocess Technol. 3(5):772-777.

Murashige, T. and F. Skoog. 1962. A revised medium for rapid growth and bioassay with tobacco tissue cultures. Physiol. Plant. 15:473497.

Nas, M.N. and P.E. Read. 2001. Micropropagation of hybrid hazelnut: Medium composition, physical state and iron source affect shoot morphogenesis, multiplication and explant vitality. Acta Hort. 556:251-258.

Ostrolucká, M.G., A. Gajdošová, and G. Libiaková. 2002. Influence of zeatin on microclonal propagation of Vaccinium corymbosum L. Propag. Ornam. Plants 2:14-18.

Ostrolucká, M.G., G. Libiaková, E. Ondrušková, and A. Gajdosová. 2004. In vitro propagation of Vaccinium species. Acta Universitatis Latviensis. Biology (Basel) 676:207-212.

Prodorutti, D., I. Pertot, L. Giongo, and C. Gessler. 2007. Highbush blueberry: Cultivation, protection, breeding and biotechnology. Eur. J. Plant Sci. Biotechnol. 1(1):44-56.

Rafi, S., A.N. Kamili, B.A. Ganai, M.Y. Mir, and J.A. Parray. 2018. In vitro Culture and Biochemical Attributes of Bergenia ciliata (Haw.) Sternb. Proc. Natl. Acad. Sci., India, Sect. B Biol. Sci. 88(2):609-619.

Reed, B.M. and A. Abdelnour-Esquivel. 1991. The use of zeatin to initiate in vitro cultures of Vaccinium species and cultivars. HortScience 26:1320-1322.

Ružić, D., T. Vujović, G. Libiakova, R. Cerović, and A. Gajdošova. 2012. Micropropagation in vitro of highbush blueberry (Vaccinium corymbosum L.). J. Berry Res. 2(2):97-103. 
Samad, N.B., T. Debnath, M. Ye, M.A. Hasnat, and B.O. Lim. 2014. In vitro antioxidant and antiinflammatory activities of Korean blueberry (Vaccinium corymbosum L.) extracts. Asian Pac. J. Trop. Biomed. 4(10):807-815.

Shibli, R.A., M.A.L. Smith, and R. Nasr. 1997. Iron source and cytokinin mitigate the incidence of chlorosis and hyperhydration in vitro. J. Plant Nutr. 20:773-781.

Spiller, S. and N. Terry. 1980. Limiting factors in photosynthesis: II. Iron stress diminishes photochemical capacity by reducing the number of photosynthetic units. Plant Physiol. 65(1):121-125.

Tetsumura, T., Y. Matsumoto, M. Sato, C. Honsho,

K. Yamashita, H. Komatsu, Y. Sugimoto, and H. Kunitake. 2008. Evaluation of basal media for micropropagation of four highbush blueberry cultivars. Scientia Hort. 119(1):72-74.

Thomas, P., J.B. Mythili, and K.S. Shivashankara. 2000. Effects of photo-oxidative loss of $\mathrm{FeNa}_{2}$ EDTA and of higher iron supply on chlorophyll content, growth and propagation rate in triploid watermelon cultures. In Vitro Cell. Dev. Biol. Plant 36(6):537-542.

Van der Salm, T.P., C.J. Van der Toorn, C.H.H. ten Cate, L.A. Dubois, D.P. de Vries, and H.J. Dons. 1994. Importance of the iron chelate formula for micropropagation of Rosa hybrida L.'Moneyway'. Plant Cell Tissue Organ Cult. 37(1):73-77.

Vescan, L.A., D. Pamfil, D. Clapa, A. Fira, C.R. Sisea, I.F. Pop, I.V. Petricele, O. Ciuzan, and R.
Pop. 2012. Efficient micropropagation protocol for highbush blueberry (Vaccinium corymbosum L.) cv. 'Elliot'. Rom. Biotechnol. Lett. 17(1):6893-6902.

Zawadzka, M. and T. Orlikowska. 2006. Increae in the quality of raspberry cultures under the influence of FeEDDHA. Acta Hort. 725:161164.

Zhang, Z., H. Liu, L. Wu, and Y. Li. 2006. Technical system of blueberry micropropagation in China. Acta Hort. 715:421-426.

Zheng, W. and S.Y. Wang. 2003. Oxygen radical absorbing capacity of phenolics in blueberries, cranberries, chokeberries, and lingonberries. J. Agr. Food Chem. 51(2):502509 